\title{
Gross Anatomical, Histological and Histochemical Studies of Thyroid Glands of African Giant Rat (Cricetomys gambianus- Waterhouse, 1840)
}

\author{
${ }^{1}$ Enemali, F.U., ${ }^{2}$ Hambolu,J.O., ${ }^{1}$ Alawa,J.N and ${ }^{1}$ Anosike,I.V \\ ${ }^{I}$ Department of Human Anatomy, Faculty of Basic Medical Sciences Bingham University, Karu; \\ ${ }^{2}$ Department of Vet Anatomy, Faculty of Veterinary Medicine Ahmadu Bello University, Zaria Correspondence: \\ Enemali, F.UDepartment of Anatomy, Faculty of Basic Medical Sciences, Bingham
}

\begin{abstract}
The wild African giant rat is currently explored as a laboratory model for scientific research. The present study is aimed at investigating the gross morphology, histology and histochemistry of the thyroid gland of wild African giant pouched rat. Twenty wild African giant pouched rats comprising of ten males and ten females were used for this study and they were humanly sacrificed using chloroform. Their thyroid glands were removed measured, weighted processed stained with $H \& E$ and special stain. The result showed that the average weight the average weight of adult male and female AGR were observed to be $1210.00 \pm 56.70 \mathrm{~g}$ and $911.11 \pm$ $24.50 \mathrm{~g}$ respectively. The weight showed sexual dimorphism with the male significantly higher than the female. Gross morphological studies of thyroid glands showed a bi-lobed organ located on the lateral surface of the trachea. The two lobes of the gland were joined together towards the superior poles by an isthmus. The result showed that the weight of the male thyroid glands was $1.28 \pm 0.03 \mathrm{~g}$ while that of the female AGR was 1.16 $\pm 0.01 \mathrm{~g}$ significantly higher than that of the female African giant rat $(P<0.05)$ hence showed sexual dimorphism. The length and width of glands do not show sexual dimorphism. Histological studies showed that the thyroid of the African giant rat consisted of follicles surrounded by follicular cells of various shapes suggesting different level of activity of the follicles. Colloids in the follicles were stained positive with periodic acid Schiff stain indicating that glycoprotein was present. Parafollicular cells were present in between the follicles of the glands similar to that of humans.
\end{abstract}

Keywords: African giant rat, gross morphology, histochemistry, thyroid gland, sexual dimorphism.

\section{Introduction}

The thyroid is one of the endocrine glands which secrete thyroglobulin, triiodothyronine and thyroxin hormones (Banks, 1993). Thyroxin plays an important role in metabolism of the animal body. Thyroid gland is present in all mammals consisting of follicles lined by follicular cells. The inter follicular space has been reported to be filled with connective tissue and blood vessels (Leeson and Leeson, 1970). The most outstanding feature of the vertebrate thyroid gland is its ability to concentrate large amount of iodine for the synthesis of thyroxin (Turner, 1966). The morphology of the gland has been reported for African grass cutter (Igbokwe, 2010), Camel (Camelus dromedarius) (Kausar and Shabid 2006), cattle, dog and sheep (Mc Donald,2003), In rat and Mouse (Ingbar, 1985). Paucity of literature on the anatomy, histology and histochemistry of thyroid gland in wild African giant rat prompted us to undertake this research work with the view of establishing some baseline data.

\section{Materials And Methods}

In this research, twenty adult African giant pouched rats of both sexes were used. The animals were captured alive using local metal cage traps in the wild around Samaru and Bomo villages in Sabogari local government area of Kaduna state, Nigeria. They were transported to the laboratory of the Department of Human Anatomy, Ahmadu Bello University, Zaria and acclimatized for two weeks prior to the research. They were fed with groundnut pellets and water was allowed ad libitum. The care and handling of these animals conformed to the rules and guidelines issued by the Ahmadu Bello University. Physical examination revealed that the animals were healthy and in good nutritional status before the research. The animals were anaesthetized using chloroform in a closed container (Adeyemu and Oke, 1990). Their body weights were recorded to the nearest gram, using a laboratory balance (Model P 1210). The animals were humanly sacrificed and an incision was made in its cervical region, the thyroid glands were dissected. The thyroid glands were located on the lateral aspect of the trachea. Photograph of glands were taken before glands were dissected. The weight of glands was determined using the digital weighing balance while the lengths and widths were determined using ruler. The glands were fixed in Bouin's fluid for $24 \mathrm{hrs}$. The fixed tissues were then dehydrated in a series of ascending ethanol concentration ( $70 \% .80 \%, 90 \%$ and $100 \%$ ), cleared in xylene, impregnated in liquid paraffin wax and 
embedded in paraffin blocks. Sections of $6 \mu \mathrm{m}$ thickness were cut using rotary microtome, dewaxed in xylene, hydrated in series of descending ethanol concentration, stained with haematoxylin and eosin and mounted on glass slides. For histochemical studies the thyroid glands were stainded with PAS for the demonstration of glycoprotein in the gland. Slides were studied on the binocular light microscope Olympus at different magnifications (X100,X200, X300 and X400 respectively).

\section{Statistical Analysis}

Data on weights, lengths and widths were expressed as mean \pm standard error of mean and statistical analysis of the data was analysed using the Student T-test for differences between males and females rats using student package for social sciences version 17.

\section{Gross and morphological studies}

\section{Results}

Gross studies of the thyroid gland of the AGR showed that it was a bi-lobed organ located on the anterior surface of the trachea (Fig 1). The two lobes were joined together at superior end by an isthmus. Glands were seen as long reddish bodies which were oval in shape with a smooth surface (Fig 1). Table 1 showed that thyroid weight showed sexual dimorphism with the male significantly higher than the female African giant rat $(\mathrm{P}<0.05)$. The length and width of the gland does not showed sexual dimorphism.

Table 1: Morphometric studies of thyroid gland of the African giant rat. (AGR)

\begin{tabular}{|l|l|l|l|l|l|}
\hline Sex of AGR & Body weight $(\mathbf{g})$ & Organ weight $(\mathbf{g})$ & Thyroid index (\%) & Organ length $(\mathbf{c m})$ & Organ Width (cm) \\
\hline M & $1210.00 \pm 56.67 *$ & $1.28 \pm 0.03^{*}$ & $0.106 \pm 0.01$ & $2.12 \pm 0.03$ & $0.56 \pm 0.013$ \\
\hline F & $911.11 \pm 24.45$ & $1.16 \pm 0.01$ & $0.127 \pm 0.01$ & $2.02 \pm 0.07$ & $0.16 \pm 0.01$ \\
\hline
\end{tabular}

Analysis by $\mathrm{T}$-test between $\mathrm{M}$ and $\mathrm{F}$

Data is expressed in mean \pm standard Error of mean (SEM) of values collected.

$*=\mathrm{P}<0.05$ (Significant between $\mathrm{M}$ and $\mathrm{F}$ )

$\mathrm{M}$ is African giant rat, $\mathrm{F}$ is female African giant rat.

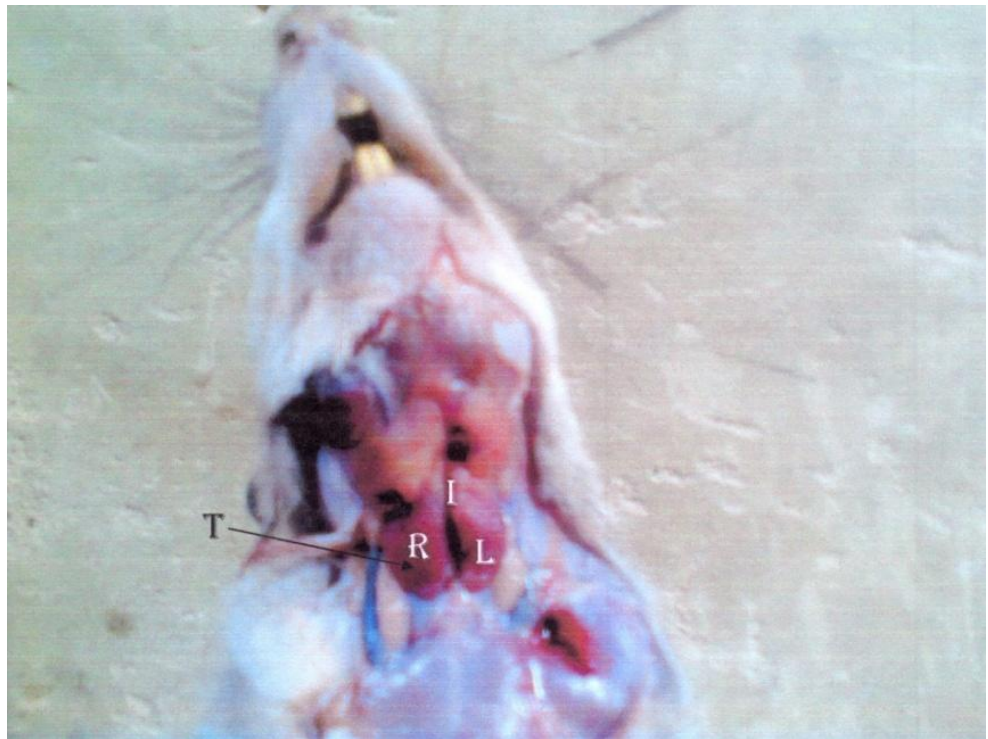

Fig1: The thyroid gland (T) of African giant rat. Note the location of the Isthmus (I) connecting the two lobes

(L) of the gland on the anterior end of the thyroid gland of the African giant rat

\section{Histology and histochemistry}

The thyroid gland was seen to consist of lobules. Each lobule consisted of an aggregation of follicles, each follicle being surrounded by basement membrane. The shapes of the follicles were round, oval and irregular (fig 2).Follicles include large, medium and small sized ones. Follicles were basically lined by cubiodal epithelium. The small sized follicles were lined by high simple cubiodal epithelium (fig 2). The medium sized follicles were equally lined by simple cubiodal epithelium with flattened nuclei (fig 2). The large sized follicles had low simple cubiodal epithelium (fig 1). Parafollicular cells were also seen between the follicles and the follicular epithelium (fig 2). A histochemical study reveals that thyroid follicles contained colloid that was PAS positive (fig3). The thyroid gland also consist of a thin net-work of inter follicular tissue made up of fibres and 
blood capillaries surrounding each follicles. Follicular space of the follicles which filled with colloids some contained only small amount and few were completely devoid of substance (fig I).

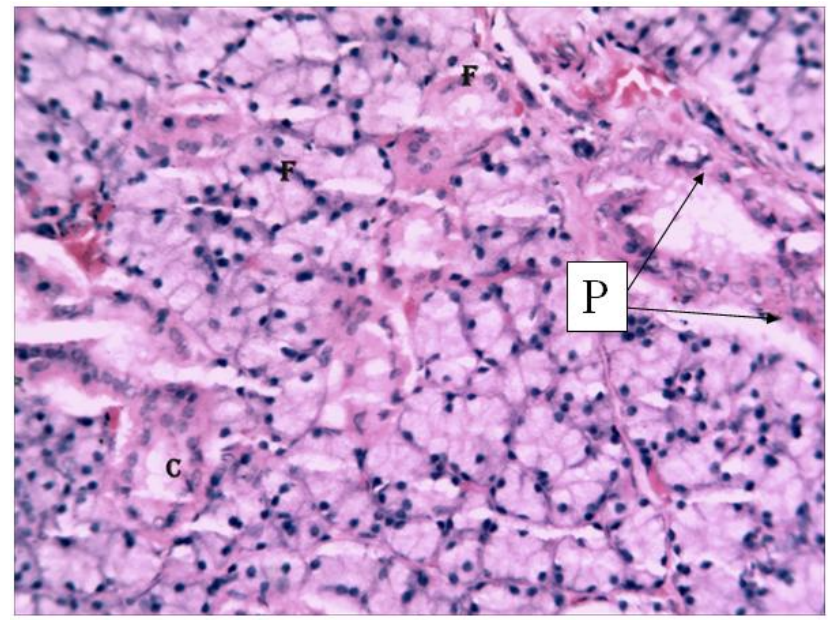

Fig 2: Micrograph of thyroid gland in African giant rat showing follicles of different sizes and at different level of activity. Note the cubiodal epithelium of follicular cells (F) surrounding the colloids (C) of different sizes of the gland. Note the parafollicular (P) cells between follicles and follicular epithelium (H\&E, X 250).

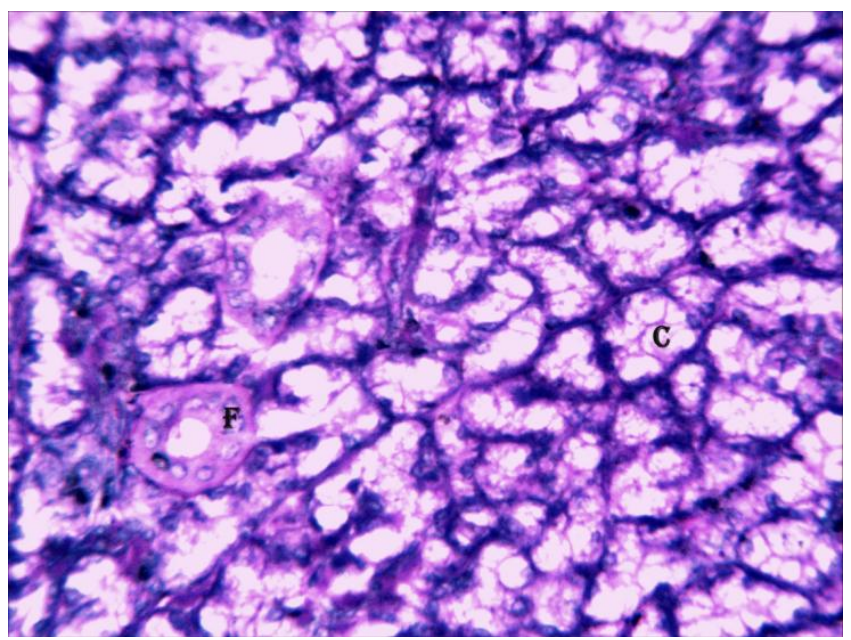

Fig3: Micrograph of thyroid histology of the African giant rat. Glandular duct (F) more consistent and regular epithelium and lumen while follicles are foaming showing presence of colloids (C) stained red with PAS (PAS stain X 250).

\section{Discussion}

In this study the location of thyroid gland in AGR is similar to other mammals like the Wistar rat (Ingbar, 1985) and in humans (Moore and Dalley, 2006). The glands were seen at the level of the first ring of trachea and consisted of two lobes on both sides and isthmus connecting these lobes. In the mice, the thyroid gland consisted of two elongated oval lobes, one on each side of the trachea, joined near their posterior poles by a thin isthmus crossing the trachea ventrally, but in the AGR, the isthmus was seen connecting the two lobes in the anterior end of the glands. The gland appeared reddish brown in colour which is similar to the findings in Grass cutter (Igbokwe, 2010). Variation in the weight of the gland was in line with past report on Wistar rat (Ingbar, 1985) and mammals (Ameda, 1987). Furthermore, study have shown that the weight of thyroid glands in the female mice were heavier than those of their male rat counterpart. However, this was not the case in this study as the weight of male thyroid gland was more than their female counterpart. The length and width of the thyroid glands of AGR were more than that of mice but it was less than that of pig, dog and humans (Lawson et al., 1998). Correlating the weight of gland with the body weight showed that there was positive correlation which was statistical significant.

The general histological features of the thyroid glands of AGR were similar to those of other mammals (Abdel-Wahab et al., 1970 and Abdel-Magied et al, 2000). The histological sections also revealed that the shapes and sizes of these follicles were not the same. Some of the follicles were large, others were medium and 
some were small. This is in agreement with the report of Hartoft-Nielsen et al, (2005) in several mammals. The general large follicle containing large amount of colloid was not observed. (Kausar and Shahid 2006) and Mathur (2004) reported that in the cow, pig, dog buffalo rabbit and guinea pig, large follicles have cubiodal epithelial cells. The present observations are in agreement with these findings. Variations in follicular sizes and epithelial height in thyroid gland of AGR are in agreement with those seen in humans and other mammal (Abdel-Margied et al, 2000). Hormonal assays result suggested that the follicular cells were actively involved in the production of the thyroid hormones, triiodothyrinine and tetraiodothyronine. The variation in the size of the follicles and heights of the follicular cells suggest that follicles and follicular cells have different level of activity within the gland. Actually the sceretory thyroid tissue is composed of smaller follicular cells lined by cubiodal cells while less active tissue is characterized by larger follicles lined by flat epithelial cells and contain large amount of colloid. Thyroid activity as measured by secretion rates is different in females and male with the T3 significantly higher in female than in male. This is in agreement with findings in mice and rats (Abdel-Margied et al, 2000). Parafollicular cells (C-cells) were found in the gland. This is agrees with the observation made in cow, buffalo, pig and in elephant (Little, 1991) and in rats. Parafollicular cells are responsible for the secretion of a hormone called calcitonin, which is a physiological antagonist to parathyroid hormone and therefore lowers blood calcium levels by suppressing the oesteoclastic resorption of bone (Singh, 2006). The follicles were PAS positive an indication that the follicular cells were actively involved in the formation of colloids present in the follicles.

\section{Conclusion}

The gross, histological and histochemical studies of the thyroid glands of the African giant rat showed sexual dimorphism and the cellular morphology could help in understanding the biology of the rodent.

\section{References}

[1]. Abdel-Margied, E. M, Taha, A.A, Abdalla, A. B. (2000). Light and Electron Microscopic Study of Thyroid gland of Camel (Camelus dromedaries)

[2]. Abdel-Wahab, M. F. and A. E. Hamza, (1970). Thyroxin contents in thyroid glands of domestic animals. IV. Thyroid activity of camel, cattle, sheep and goats in Sudan. Endokrinologie, 56: 206-212

[3]. Adeyemu, O. and Oke, B.O. (1990). Companies of the Testicular and Epididymisis Protein of the AGR (Cricitomys gambians) and Laboratory Rats. Journal of Tropical Vegetarian 8: 17-27

[4]. Ameda Y. (1987). Localisations of immunoreactive calcitoni gene-related peptide in thyroid C cells from various mammalian species. Anatomical Record, 219: 204-212.

[5]. Banks, W. J. (1993). Endocrine System in Applied Veterinary Histology. 3rd Edition, Mosby Books Incorporated, USA PP.408-428.

[6]. Capen, C. and Martin, S.L. (2003). The Thyroid Gland, Veterinary Endocrinology and Reproduction, $5^{\text {th }}$ Edition. Lowa State Press, Ames, Lowa PP. 35-69.

[7]. Hartoft-nielsen ML, Rasmussen AK, Buschard, K, Block T. (2005). Estimation of Number of Follicles, Volume of Colloid and Inter follicular Surface Area in the Thyroid Glands of Rats Journal of Anatomy 207: 117-124

[8]. Igbokwe C.O. (2010) Gross and Micoscopic Anatomy of Thyroid Gland of the wild African Grass cutter in Southern Nigerian, Enviromental Journal of Anatomy 14 (1): 5-10.

[9]. Ingbar S.H. (1985). The thyroid in: Book of Endocrinology London press, Pp 682-688.

[10]. Lawson V Y and Carrick F.N (1998). Morphology of the Thyroid in Coastal and Non Coastal Populations of the Koala in Queensland. General Comp Endour, 110: 295-306.

[11]. Little G.J (1991) Thyroid Morphology and Function and its Role in Thermoregulation in New Born Southern Elephant. Journal of Anatomy 176: 55-69.

[12]. Marthur M.L (2000). Microscopic study of the thyroid gland of the Asiatic water buffalo (Bubalis bubalis). American Journal of Veterinary Research, 32: 363-367.

[13]. Moore, Keith L.; Dalley, Arthur F,(2006) Clinically Oriented Anatomy, fifth Edition.

[14]. Singh Inderbir, (2006) Text book of Human Histology fifth edition Jaypee Brothers Medical publishers (P) Ltd New Delhi PP. 313318

[15]. Leeson, T. S. and C. R. Leeson, 1970. Histology, 2 Edition. W. B. Saunders Company, Philadelphia, USA.

[16]. Turner, C. D., 1966. General Endocrinology, 4 Edition, W. B. Saunders Company, London, UK. 